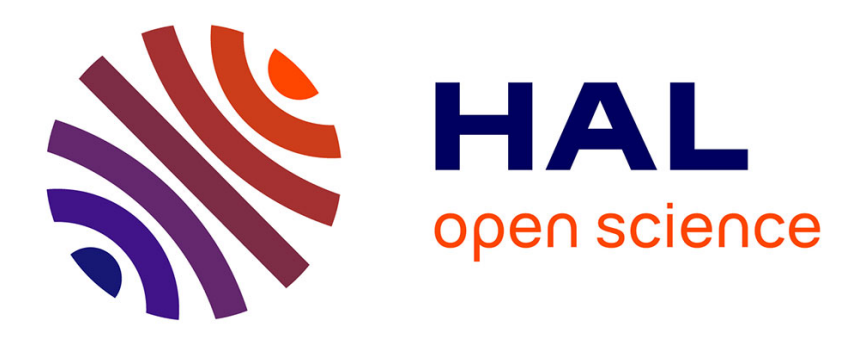

\title{
Dual-Notch Void Model to Explain the Anisotropic Strengths of 3D Printed Polymers
}

\author{
L. Xu, Dominique Leguillon
}

\section{To cite this version:}

L. Xu, Dominique Leguillon. Dual-Notch Void Model to Explain the Anisotropic Strengths of 3D Printed Polymers. Journal of Engineering Materials and Technology, 2020, 10.1115/1.4044282 . hal02878727

\section{HAL Id: hal-02878727 https://hal.sorbonne-universite.fr/hal-02878727}

Submitted on 23 Jun 2020

HAL is a multi-disciplinary open access archive for the deposit and dissemination of scientific research documents, whether they are published or not. The documents may come from teaching and research institutions in France or abroad, or from public or private research centers.
L'archive ouverte pluridisciplinaire HAL, est destinée au dépôt et à la diffusion de documents scientifiques de niveau recherche, publiés ou non, émanant des établissements d'enseignement et de recherche français ou étrangers, des laboratoires publics ou privés. 
ASME J. of Engineering Materials and Technology (Paper \# MATS-19-1054) April 20, 2019

\title{
Dual-Notch Void Model to Explain the Anisotropic Strengths of 3D Printed Polymers
}

\author{
L. Roy $\mathrm{Xu}^{1, *}$ and Dominique Leguillon ${ }^{2}$ \\ ${ }^{1}$ Department of Mechanical Engineering, University of New Mexico \\ Albuquerque, NM 87131, USA \\ ${ }^{2}$ Institut Jean Le Rond d'Alembert, CNRS UMR7190, \\ Sorbonne Université, 4 place Jussieu, 75005 Paris, France
}

\begin{abstract}
Based on the unique additive manufacturing process, a dual-notch void model is proposed to explain three tensile strengths of a 3D printed polymer along three major directions. This model incorporates the strength/notch angle relation, and provides a relative magnitude of three tensile strengths, i.e., $S_{x}$ (axial strength) $>S_{y}$ (transverse strength) $\geq S_{z}$ (inter-layer strength).

\section{Introduction}

Additive manufacturing (AM), aka 3D printing is defined as the process of joining materials to create objects directly from 3D models, usually layer upon layer. AM's advantages include design flexibility, customized geometries and low volume production, short design-tomanufacture cycle times, and reduced assembly time [1-5]. However, 3D printed materials for structural applications have a huge challenge. These materials can be treated as isotropic materials in terms of stiffness. Unlike traditional isotropic materials such as polymers and metals, strengths and fracture toughnesses of 3D printed materials are highly anisotropic or very different along different loading directions [6-12]. This feature is a result of the unique additive manufacturing process, because numerous interfaces and voids exist at printing surfaces and rasters due to the layer-by-layer process. The purpose of this paper is to provide a simple comparison of the anisotropic strengths of 3D printed polymers based on an idealized void model, and only fused deposition modeling is considered in this paper [13].
\end{abstract}

\section{Dual-notch void model based on material processing}

According to Brenken et al., the bond formation between rasters (or beads) is of great importance for the mechanical performance of printed parts using fused deposition modeling [13]. An illustration of the bond formation process for round-shaped extruded rasters is provided in Figure 1. All rasters shown in Figure 1 have the same direction (unidirectional rasters). Here we define the $\mathrm{Z}$-axis as the build direction, the $\mathrm{X}$-axis is along the raster direction (longitudinal or axial direction), and the $\mathrm{Y}$-axis is perpendicular to the raster direction or the transverse direction. When two rasters get in contact, a neck between these rasters starts to form. Once a connection is established, polymer chains diffuse through the interface and a randomization takes place concluding the process. The above neck formation process was observed in a sintering experiment of printed Acrylonitrile Butadiene Styrene (ABS) polymers. Therefore, Rezaee and Adnan proposed a sharp notch model and assumed that a large concave notch forms between two rasters

\footnotetext{
*corresponding author, Phone 1-915-342-0700, Electronic mail: luoyu.xu@yahoo.com
} 
[14]. This notch angle may increase to its maximum value of $180^{\circ}$ (large notch angle). Indeed, this notch leads to a stress concentration which exists in a classic plate with a central hole subjected to remote tension, when these rasters are subjected to remote horizontal tension along the $\mathrm{Y}$ direction. This mechanism can explain that the transverse strength of cured rasters is always lower than their longitudinal strength, because no stress concentration of rasters is involved during longitudinal tension along the $\mathrm{X}$-axis.
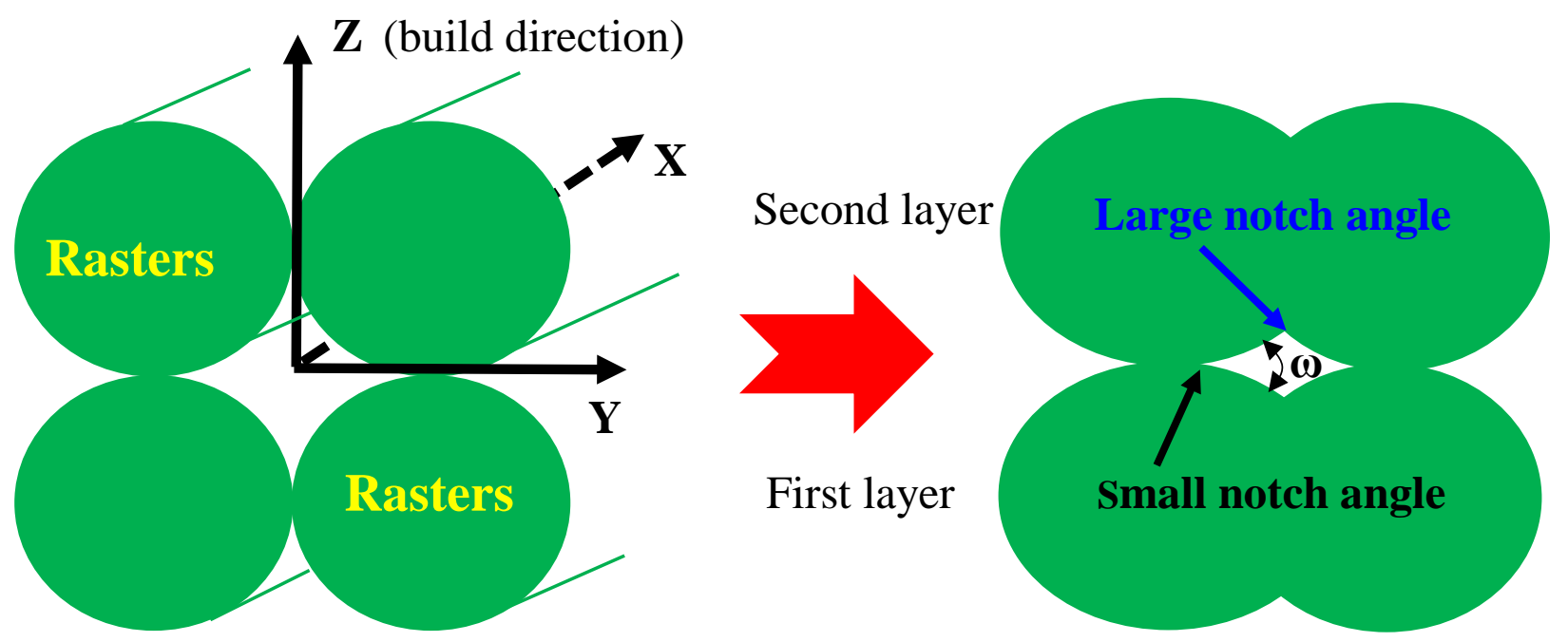

Figure 1. Cross-sectional views of the bond formation process between adjacent rasters and an idealized defect forms between the rasters and printing surfaces, and $\omega$ is the notch opening angle.

We extend the above observation/model to provide more mechanics insights. After the first layer of rasters is printed, the second layer of rasters stacks on the first layer as shown in Figure 1. So an idealized "dual-notch void" forms between four rasters and two layers. There are two notch angles, i.e., the large notch angle is between two rasters and the small notch angle is between two layers. Because of the weight of the second and other top layers, we expect that the large notch angle will tend to be $180^{\circ}$, while the small notch angle will be close to $0^{\circ}$.

\section{Influence of the notch angle on the material strength}

The effect of the notch angles on the material strengths was extensively studied by the authors and other researchers [15-21]. Carpinteri found that the measured strengths of Polymethyl Methacrylate (PMMA) beams with different notch angles were an increasing function of the notch angles as shown in Figure 2 [20]. If the notch angle $\omega$ was $180^{\circ}$, there is no stress singularity/concentration, so we define the strength as $100 \%$. If the notch angle $\omega$ was $0^{\circ}$, the strength problem became a fracture mechanics problem, and the normalized strength reached the lowest value (around 17\%). For the dual-notch void, the large and small angles will lead to different strengths along different load directions.

Herein we employ an approach within the Finite Fracture Mechanics (FFM) framework [15-16], the so-called coupled criterion (CC) [17-18]. It is assumed that for crack nucleation at a stress concentration point (e.g., a notch tip), an energy and a stress condition must be simultaneously fulfilled. As a consequence, in general the crack jumps a finite length and then can either stop or grow in a stable or unstable manner. More precisely, the CC states that a crack with a length $l$ appears if: (i) the energy balance is fulfilled 


$$
W_{\mathrm{P}}(0)-W_{\mathrm{P}}(l) \geq G_{\mathrm{c}} l
$$

where $W_{\mathrm{P}}(l)$ denotes the potential energy of a material embedding a crack with a length $l$, and $G_{\mathrm{C}}$ is the fracture energy of the material, equivalent to the fracture toughness $K_{\text {Ic }}$ through Irwin's relationship ( $v$ is the Poisson's ratio and $E$ the Young's modulus)

$$
G_{\mathrm{c}}=\frac{1-v^{2}}{E} K_{\text {Ic }}^{2}
$$

(ii) The tensile stress $\sigma$ exceeds the tensile strength $\sigma_{\mathrm{c}}$ all along the presupposed crack path prior to crack initiation

$$
\sigma(r) \geq \sigma_{\mathrm{c}} \text { for } 0 \leq r \leq l
$$

Note that, as often $\sigma(r)$ is a decreasing function of $r$, thus (3) is equivalent to

$$
\sigma(l) \geq \sigma_{\mathrm{c}}
$$

As a consequence of the two inequalities (1) and (4), initiation is brutal and the crack jumps a finite length $l_{\mathrm{c}}$ (it is infinitesimal only in the case of the growth of a pre-existing crack). Solving the two inequalities allows determining both $l_{\mathrm{c}}$ and the load at failure. Moreover, it must be pointed out, that the CC coincides with the well-known Griffith's criterion in case of a pre-existing crack $\left(\omega=0^{\circ}\right)$, and with the maximum sustainable tensile stress for a plain (straight-edge) specimen without a notch $\left(\omega=180^{\circ}\right)$.

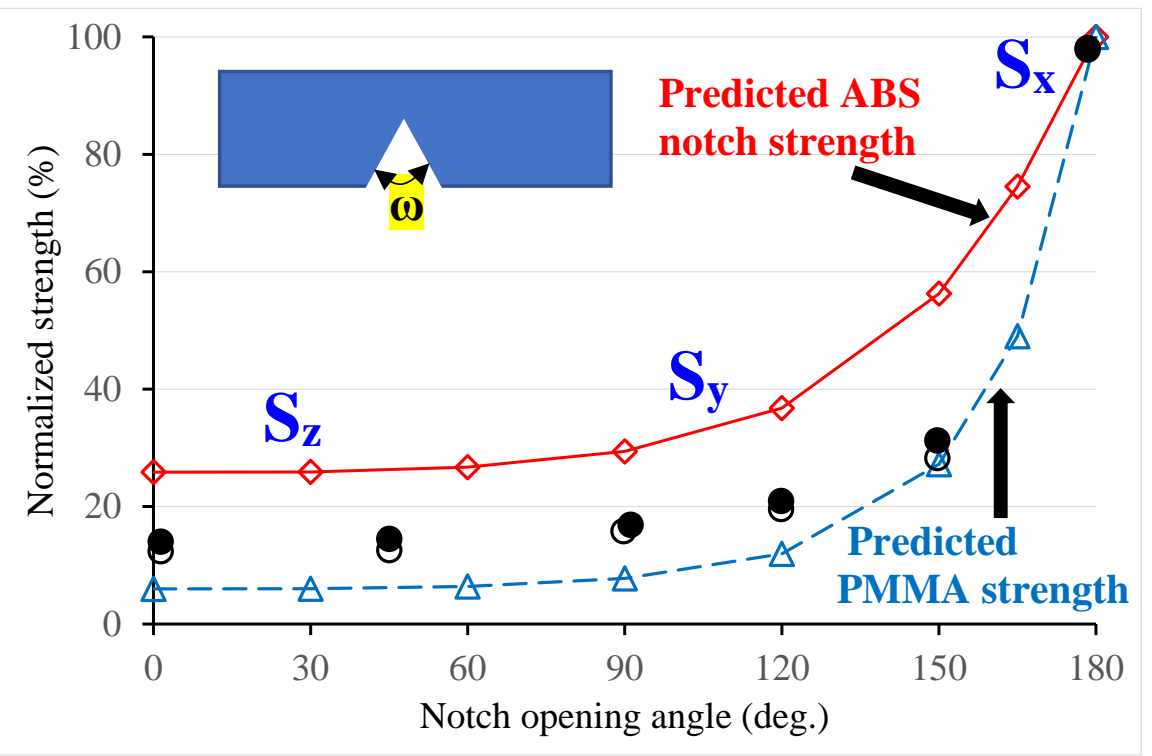

Figure 2. Predicted normalized notch strength as a function of the notch opening angle $\omega$. The blue dashed line and triangles represent large PMMA specimens (notch depth $10 \mathrm{~mm}$ ), and the solid red line and diamonds represent ABS specimens. Carpinteri's previous measured PMMA strengths are shown as circles. $S_{x}, S_{y}$, and $S_{z}$ are only illustrations of three tensile strengths (relative not absolute values) of $3 D$ printed materials related to different notch opening angles. 
The CC can be implemented using a full finite element procedure, by computing (1) and (4) for various virtual crack length $l$. There is also an asymptotic approach based on Williams' expansion of an elastic solution in the vicinity of a notch, we refer to $[17,21]$ for a detailed presentation of this quasi-analytic approach. Results obtained by the asymptotic approach are shown in Figure 2 for double-edge-notched specimens of $\mathrm{ABS}\left(E=2 \mathrm{GPa}, v=0.25, K_{\mathrm{Ic}}=2.7\right.$ $\mathrm{MPa} \mathrm{m}^{1 / 2}, \sigma_{\mathrm{c}}=46 \mathrm{MPa}$ of raw ABS $)$ and PMMA $\left(E=2.5 \mathrm{GPa}, v=0.25, K_{\mathrm{Ic}}=0.97 \mathrm{MPa} \mathrm{m}^{1 / 2}, \sigma_{\mathrm{c}}\right.$ $=70 \mathrm{MPa}$ of raw PMMA). ABS is commonly used as a 3D printed material, and PMMA is a brittle polymer. Our prediction generally agreed with Carpinteri's experiments well. It is important to notice that in Carpinteri's experiments, the notch depth was $10 \mathrm{~mm}$ while the notch depth of 3D printed polymers is very small $(<1 \mathrm{~mm})$ because their notch depths are functions of different raster diameters and other factors. In Figure 2, three relative tensile strengths $\left(S_{x}, S_{y}\right.$, and $\left.S_{z}\right)$ are marked for illustration purpose (not absolute values), since the notch strength prediction was not for three tensile strengths of 3D printed polymer specimens.

The strength vs notch angle relation can be employed to explain the relative magnitudes of three strengths: (1) if remote tension is applied along the raster direction (X-axis), we can measure the axial (or longitudinal) strength $S_{x}$, (2) if tensile load is applied along the transverse direction (Y-axis), we can measure the transverse strength $S_{y}$, and (3) if tensile load is applied along the outof-plane (or inter-layer) direction (Z-axis), we can measure the inter-layer strength $S_{z}$ as shown in Figure 3. These three strengths are independent, but their magnitudes can be estimated using the strength and notch angle relation. First, measuring $S_{\mathrm{x}}$ has no stress concentration involved ( $\omega$ $=180^{\circ}$ ), so $S_{x}$ has the highest strength as illustrated in Figure 2. Second, according to Figures 1 and 3 , the notch angle related to $S_{y}$ is larger than the notch angle related to $S_{z}$, therefore, we illustrate these two strengths in Figure 2. However, if the notch angle is smaller than $120^{\circ}$, the difference of two strengths which are related to two notch angles is small, or their measurements could be very close. Finally, we can obtain a simple magnitude relation among three strengths:

$$
\text { Sx (axial strength) }>\text { Sy (transverse strength) } \geq \text { Sz (inter-layer strength) }
$$
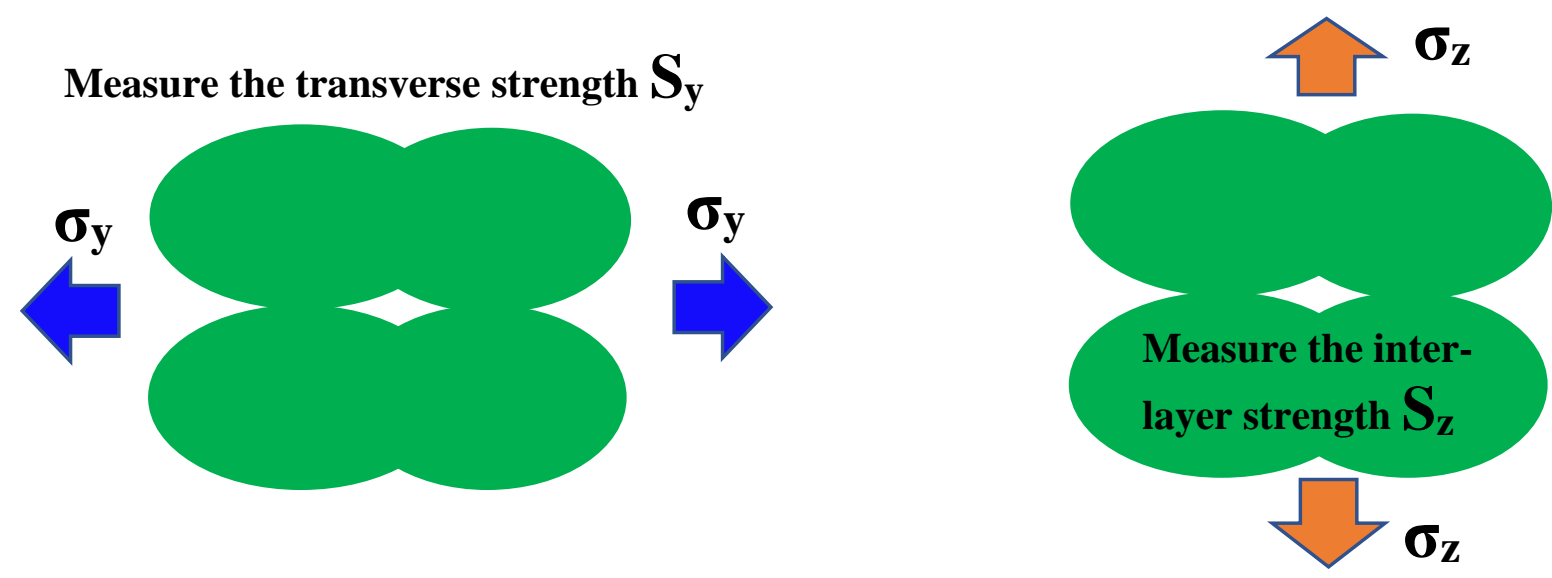

Figure 3. Remote tensile tests to measure the transverse/inter-layer strengths $S_{y}$ and the Sz.

When tensile load is applied to measure the transverse strength $S_{y}$, only the large notch angle leads to a tensile stress concentration. While the stress field at the small notch angle is compressive, which is similar to the stress distribution along a central hole of a large plate subjected to remote tension. So we do not consider the small notch angle because it makes no 
contribution to the tensile strength. A similar situation is also applicable to $S_{z}$ measurement. Indeed, sharp notches do not exist in materials and all notches are rounded. The purpose of our sharp notch assumption is that sharp notch angles are easy to compare using the same mechanics theory. However, rounded notches have finite radii, and the small and large notch angles have different radii, so it is not easy to compare their stress singular orders/concentrations and draw a simple conclusion in this short paper. Also, plastic deformation should occur at these notch tips. But our conclusion still holds because high stress concentrations exist at these notches even these notches are rounded or have plastic deformation. Therefore, we will conduct further investigation on these complex research topics.

\section{Results and Discussion}

Table 1. Anisotropic tensile strengths (MPa) of selected 3D printed polymers

\begin{tabular}{|c|c|c|c|c|}
\hline Authors & Material & $\begin{array}{ll}\text { Sx } & \text { (axial } \\
\text { strength) }\end{array}$ & Sy(transverse strength) & Sz (inter-layer strength) \\
\hline Song et al. [6] & PLA & $54.89\left(0^{\circ}\right.$ raster $)$ & $46.24\left(90^{\circ}\right.$ raster $)$ & 36 \\
\hline $\begin{array}{l}\text { Torrado \& } \\
\text { Roberson [22] }\end{array}$ & ABS & 34.5 & 28.6 & 29.5 \\
\hline $\begin{array}{l}\text { Khatri \& Adnan } \\
\text { [12] }\end{array}$ & $\mathrm{ABS}$ & 20.69 & 9.59 & \\
\hline $\begin{array}{l}\text { Huang \& } \\
\text { Singamneni[23] }\end{array}$ & ABS & 30.96 & 10.8 & \\
\hline Zou et al. [24] & ABS & 27.63 & & 25.74 \\
\hline Riddicket al. [5] & $\mathrm{ABS}$ & 32.60 & & 15.14 \\
\hline
\end{tabular}

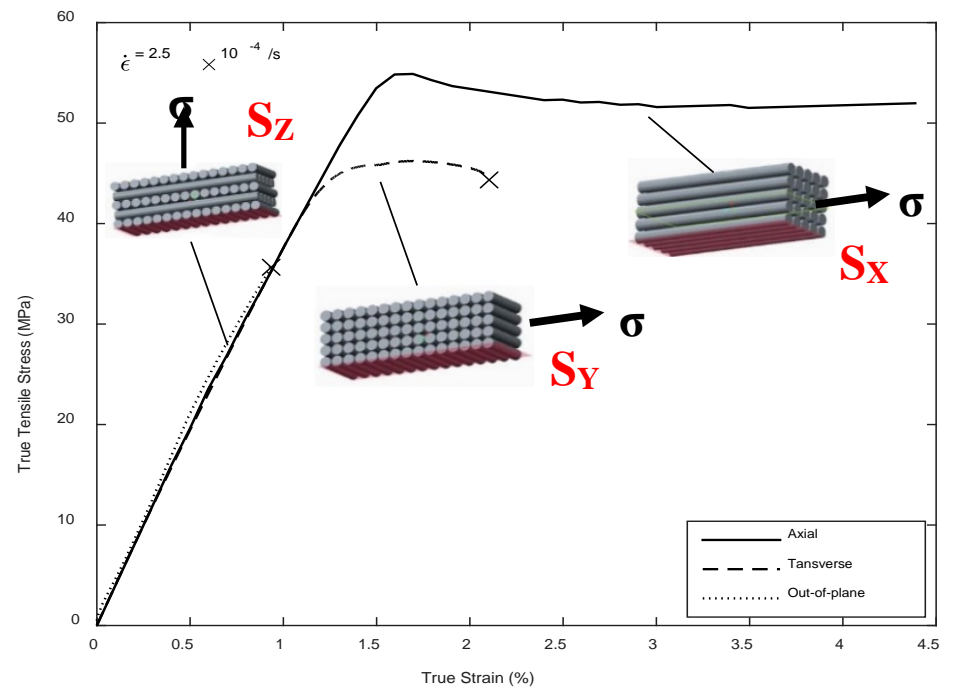

Figure 4. Measured three tensile strengths of a 3D-printed PLA polymer [6] 
We only find that Song et al [6], Torrado and Roberson [22] published three strength measurements of 3D printed polymers as shown in Table 1 . We added $S_{x}, S_{y}$, and $S_{z}$ notations in Figure 4 showing Song's measurements of Polylactide (PLA) specimens, so the readers can build the connections of their specimen illustrations with our strength definitions as shown in Figures 1 and 3. Their results exactly supported our conclusion: $S_{\mathbf{x}}$ (axial strength) $>S_{\mathbf{y}}$ (transverse strength) $\geq S_{\mathbf{z}}$ (inter-layer strength). In Table 1 , even other researchers' data were incomplete, these data still demonstrated the relative magnitude of three strengths. We notice that in one measurement the inter-layer strength is slightly higher than the transverse strength, but they are within the measurement error range [22]. Unlike the $80 \%$ notch strength reduction as seen in Figure 2, the reduction of tensile strengths in Table 1 is small because our proposed notch void model is an explanation, not a prediction of three tensile strengths. Moreover, there are many notch voids (rather than a single void as shown in Figure 2) in a 3D printed polymer, and the sizes of these voids vary significantly. In general, 3D printed ABS specimens show large strength variations in different measurements due to numerous defects and interfaces. For example, the highest axial strength is $67 \%$ higher than the lowest axial strength, and the highest transverse strength is $198 \%$ higher than the lowest transverse strength [12,22]. Therefore, we must pay great attention to the anisotropic strengths of 3D printed materials. One interesting phenomenon of Figure 4 is that all 3D printed specimens had the same Young's modulus (the initial slope of the stress-strain curve), although their strengths were very different. Similar experiments by Riddick et al. also showed the same trend [5]. Therefore, these experimental results exactly support our general statements: stiffness of 3D printed polymers is isotropic, while the strengths of 3D printed polymers are anisotropic.

In this paper, we only report a preliminary result on the anisotropic strengths which is not yet fully interpreted based on mechanics. There are numerous topics available for future investigation. For example, although we analyzed dual-notch voids in 3D printed polymers, similar voids also exist in 3D printed composite materials with polymeric matrices [25]. Also, triangle notch voids were observed in 3D printed polymers [5]. Our modeling can be extended to dynamic failure strengths [26]. Cole et al. found that during the printing process, the butadiene phase of ABS migrates away from the raster interfaces and the styrene-acrylonitrile (SAN) phase migrates to the interface and a non-homogeneous microstructure exists [27]. As a result, material properties at the interface are different from those of the bulk materials. Indeed, the authors developed a failure mechanics model to analyze crack initiation of a notch which is connected to an interface [21]. Application of this model to 3D printed polymers would be our future research. Moreover, the tensile strength $\sigma_{c}$ in our prediction should be the interfacial tensile strength, and there are at least two interfacial strengths along the $\mathrm{Z}$ and $\mathrm{Y}$ directions. We had to employ the tensile strengths of bulk polymers, since these interfacial strengths are not available.

\section{Conclusions}

The dual-notch void model can provide an explanation of three basic tensile strengths of a 3D printed polymer. The inter-layer (or out-of-plane) tensile strength is the lowest strength among three strengths, and this strength may limit extensive applications of 3D printed materials to structural components. Future material designs should address increasing the inter-layer strength such as modifying the shapes of rasters. 


\section{Acknowledgements}

The authors gratefully acknowledge valuable discussion with Professor Mehran Tehrani at University of Texas at Austin, and one original drawing from Drs. Yichi Song and Vito Tagarielli. We also thank two reviewers for their suggestions to improve the original manuscript and provide future research directions.

\section{Reference}

[1] Standard Terminology for Additive Manufacturing Technologies: Designation F2792-12a, ASTM International, West Conshohocken PA, 2012.

[2] R. Campbell, T.T. Wohlers, T. Caffrey, 3D Printing and Additive Manufacturing State of the Industry: Annual Worldwide Progress Report, 2016.

[3] N. Aliheidari , R. Tripuraneni , A. Ameli, S. Nadimpalli, Fracture resistance measurement of fused deposition modeling 3D printed polymers, Polymer Testing 60 (2017) 94-101.

[4] D. Lin, Q. Nian, B. Deng, S. Jin, Y. Hu, W. Wang, G.J. Cheng, Three-dimensional printing of complex structures: man made or toward nature? ACS Nano 8 (2014) 9710-9715.

[5] J. C. Riddick, M A. Haile, R Von Wahlde, D. P. Cole, O. Bamiduro, T. E. Johnson Fractographic analysis of tensile failure of ABS fabricated by FDM, Additive Manufacturing 11 (2016) 49-59.

[6] Y. Song, Y. Li, W. Song, K. Yee, K.-Y. Lee, V.L. Tagarielli, Measurements of the mechanical response of unidirectional 3D-printed PLA, Materials and Design 123 (2017) 154-164.

[7] J. Gardan, A. Makke, N. Recho, Improving the fracture toughness of 3D printed thermoplastic polymers by fused deposition modeling, International Journal of Fracture 210 (2018) 1-15.

[8] F. Arbeiter, M. Spoerk, J. Wiener, A. Gosch, G. Pinter, Fracture mechanical characterization and lifetime estimation of nearhomogeneous components produced by fused filament fabrication, Polymer Testing 66 (2018) 105-113.

[9] M. Seifi, A. Salem, J. Beuth, O. Harrysson, J. Lewandowski, Overview of Materials Qualification Needs for Metal Additive Manufacturing, JOM 68 (2016) 747-764.

[10] T. McLouth, J. Severino, P. Adams, D. Patel, R. Zaldivar, The impact of print orientation and raster pattern on fracture toughness in additively manufactured ABS, Additive Manufacturing, 18 (2017) 103-109.

[11] K. Hart, E. Wetzel, Fracture behavior of additively manufactured acrylonitrile butadiene styrene (ABS) materials, Engineering Fracture Mechanics 177 (2017) 1-13.

[12] A. Khatri, A. Adnan, Effect of raster orientation on fracture toughness properties of 3d printed abs materials and structures, Proceedings of the ASME 2016 paper \# IMECE2016-67801.

[13] B. Brenken, E. Barocio, A. Favaloro, V. Kun, R. Pipes, Fused filament fabrication of fiberreinforced polymers: A review, Additive Manufacturing 21 (2018)1-16.

[14] A. Rezaee, A. Adnan, On the elastic stress singularities and mode I notch stress intensity factor for 3D printed polymers, Engineering Fracture Mechanics 204 (2018), 235-245. 
[15] Z. Hashin, Finite thermoelastic fracture criterion with application to laminate cracking analysis, J. Mech. Phys. Solids 44 (1996)1129-1145.

[16] D. Taylor, The Theory of Critical Distances: A New Perspective in Fracture Mechanics, Elsevier, Oxford, UK, 2007.

[17] D.Leguillon, Strength or toughness? A criterion for crack onset at a notch, Eur. J. of Mechanics - A/Solids 21 (2002) 61-72.

[18] P. Weissgraeber D. Leguillon, W. Becker, A review of Finite Fracture Mechanics: crack initiation at singular and non-singular stress-raisers, Arch. Appl. Mech. 86 (2016) 375-401.

[19] A. Krishnan, L. R. Xu, Experimental Studies on the Interaction among Cracks, Notches and Interfaces of Bonded Polymers, International Journal of Solids and Structures 50 (2013) 15831596.

[20] A. Carpinteri, Stress-singularity and generalized fracture toughness at the vertex of re-entrant corners, Engineering Fracture Mechanics 26 (1987) 143-155.

[21]V.-X.Tran, D. Leguillon, A. Krishnan, L.R. Xu, Interface crack initiation at V-notches along adhesive bonding in weakly bonded polymers subjected to mixed-mode loading. International Journal of Fracture 176 (2012) 65-79.

[22] A. R. Torrado, D A. Roberson, Failure Analysis and Anisotropy Evaluation of 3D-Printed Tensile Test Specimens of Different Geometries and Print Raster Patterns, J. Fail. Anal. and Preven. (2016) 16:154-164.

[23] B. Huang and S. Singamneni, Raster angle mechanics in fused deposition modelling, Journal of Composite Materials 49 (2015) 363-368.

[24] R. Zou, Y. Xia, S. Liu, P. Hu, W. Hou, Q. Hu, C. Shan, Isotropic and anisotropic elasticity and yielding of 3D printed material, Composite B 99 (2016) 506-513.

[25] N Werken, J Hurley, P Khanbolouki, A Sarvestani, A Tamijani, M Tehrani, Design considerations and modeling of fiber reinforced 3D printed parts, Composites B 160 (2019) 684692.

[26] J. P. Isaac, H V Tippur, Quasi-Static and Dynamic Fracture Behaviors of Additively Printed ABS Coupons Studied Using DIC: Role of Build Architecture and Loading Rate, Mechanics of Additive and Advanced Manufacturing, 8 (2019) 11-19. Society for Experimental Mechanics.

[27]. D. Cole J. Riddick, H. M. Iftekhar Jaim, N. Zander, Interfacial mechanical behavior of 3D printed ABS. Journal of Applied Polymer Science 133 (2016), 43-52. 